\title{
FACES DO PRÉ-SAL BRASILEIRO: MIGRAÇÃO, TRABALHO E SOCIABILIDADE
}

\author{
Claudelir Correa Clemente $^{1}$
}

Resumo: A partir de observações etnográficas o presente trabalho apresenta experiências de trabalhadores migrantes que atuam na exploração e produção petrolífera em mares brasileiros, em especifico, trabalhadores offshore estrangeiros envolvidos nas atividades do pré-sal em área marítima denominada bacia de Santos. Essa bacia estende-se do estado do Espírito Santos ao estado de Santa Catarina é o espaço da exploração petrolífera da camada pré-sal. Em especifico, nas cidades de Macaé/RJ, Rio de Janeiro/RJ e Santos/ SP, observa-se um crescente aumento de trabalhadores estrangeiros offshore contratados por empresas transnacionais que atuam no setor. Atraídos pelo trabalho na plataforma em alto mar, pelas promessas de um excelente salário e pelos 15 dias de tempo livre, já que a maioria dos contratos trabalhistas dessas empresas estrangeiras, preveem 15(quinze) dias de trabalho e 15 (quinze) dias de folga, os trabalhadores estrangeiros acabam desenvolvendo experiências sociais que os colocam entre o mar, a terra e a origem. Para a antropologia, tais experiências apontam para criação de vínculos sociais específicos que permitem compreender algumas das formas de sociabilidade contemporânea, tornando visíveis muitas das faces que compõem a globalização.

Palavras - chave: profissionais transnacionais, pré-sal, etnografia.

Abstract: From ethnographic observations this paper presents the experiences of migrant workers working in the oil exploration and production in Brazilian seas, in specific, offshore foreign workers involved in the activities of the pre-salt offshore area known as the Santos basin. This basin extends from the state of Espírito Santo to Santa Catarina -is the space of oil exploration in the pre-salt. In specific, in the cities of Macaé / RJ, Rio de Janeiro / RJ and Santos / SP, there is an increasing number of foreign workers employed by offshore transnational corporations operating in the sector. Attracted by work on the platform at sea, by the promises of an excellent salary and the 15 days of free time, since most of the labor contracts of these foreign companies predict fifteen (15) working days and fifteen (15) days off foreign workers eventually develop social experiences that place them between the sea, the earth and the origin. For anthropology, these experiences point to the creation of specific social ties that

1 Professora Adjunta II de Antropologia do Instituto de Ciências Sociais, Universidade Federal de Uberlândia. 
$\mid 42$ |

Faces do pré-sal brasileiro...

allow us to understand some of the contemporary forms of sociability, making visible many of the faces that make up globalization.

Keyswords: transnational work, pré-sal, ethnografy.

Entre o mar, a terra e a origem: especificidades do trabalho offshore

Diariamente circulam nos heliportos de Cabo Frio/RJ, Jacarepaguá/RJ, Itanhaém/SP, Macaé/RJ, Navegantes/SC e Vitória/ ES trabalhadores offshore que atuam em plataformas ou em navios sonda utilizados na exploração e produção de petróleo em mares brasileiros. Analisarei as relações entre trabalho e sociabilidade urbana no cotidiano desses profissionais em seus momentos de folga.

Para tanto, antes farei uma breve apresentação desse universo do trabalho offshore.

Embarcados é como são conhecidos os trabalhadores offshore no universo petroleiro. É um grupo composto por operários, técnicos, engenheiros, geólogos, geofísicos e outros profissionais da área de energia. Entre eles encontram-se mulheres e homens de várias nacionalidades que, com exceção de alguns pesquisadores universitários, são empregados de empresas transnacionais atuantes no setor petrolífero.

Trabalham em unidades marítimas localizadas entre 200 e $400 \mathrm{~km}$ da costa brasileira. Seu deslocamento é feito em helicópteros que os transportam da costa ao local de trabalho.

Nas plataformas e sondas seguem um turno singular de trabalho. Se forem funcionários da empresa petrolífera Petróleo Brasileiro, a Petrobrás, trabalham durante 14 dias embarcados e dispõem de 21 dias de folga no continente. Quando são empregados de empresas estrangeiras os períodos podem variar, tanto que, nos outros países que tem atividades de extração de petróleo offshore, costuma-se prescrever os tempos de trabalho e de folga conforme o que descrevem Freitas, Souza, Machado e Porto (2001): 
Em alguns países possui uma alternância de 14/14 Reino Unido), 7/7 (Estados Unidos), ou mesmo uma progressão de 14/14 no primeiro ciclo, 14/21 no segundo ciclo e 14/28 no terceiro ciclo (Noruega). Em termos de horas de trabalho durante o período de embarque, o mais comum são 12 de trabalho para 12 de descanso, porém o período de horas efetivamente trabalhadas, incluindo as extras, frequentemente chega a ser de 14 horas. Há alguns postos de trabalho em que a jornada pode chegar a 17 horas. De qualquer modo, independentemente da modalidade de turnos estabelecida, alguns trabalhadores permanecem de prontidão durante todo o tempo em que se encontram na plataforma. Por suas características intrínsecas, o trabalho nas plataformas inclui uma ampla diversidade de atividades tais como partidas de instalações e produção; paradas e redução da produção; manuseio de equipamentos e materiais perigosos; controle manual do processo; monitoramento da produção por sistema supervisório; manutenções preventivas e corretivas; limpeza de máquinas e equipamentos; transporte de materiais; operações manuais e mecânicas de levantamento de cargas; inspeções e testes de equipamentos; transporte marítimo e aéreo; cozinha; limpeza; construção e reforma, entre outras. (Freitas, Souza e machado e Porto, 2001, p. 119).

Em linhas gerais, as pessoas que trabalham em unidades marítimas estão divididas em três áreas de atuação: área de perfuração, área de exploração e manutenção/serviços.

Na área de perfuração, concentram-se profissionais tais como engenheiros geólogos, geofisicos, perfuradores e seus ajudantes, mergulhadores e engenheiros submarinos. $\mathrm{Na}$ área de exploração, estão profissionais como biólogos químicos, operadores de máquinas, mecânicos, soldadores, eletricistas, pintores e demais operadores de petróleo. Da manutenção e serviços fazem parte cozinheiros e ajudantes de cozinha, profissionais de hotelaria, enfermeiros, médicos, administrativos, analistas de sistemas, 
engenheiros de comunicações. São trabalhadores que vivem entre o mar, a terra e a origem. Origem porque alguns, quando estrangeiros, não são moradores das cidades da costa brasileira e muitos, nem do Brasil, mas são habitantes de vários países. Entre os embarcados encontram-se argentinos, norte-americanos, chineses, noruegueses, indianos, paquistaneses, tailandeses, alguns dos quais retornam para seu país após o desembarque da plataforma.

Interessei-me em pesquisar esse grupo devido a minha trajetória antropológica centrada em estudos sobre a constituição de vínculos sociais por pessoas que vivem em deslocamentos constantes por motivo de trabalho.

Desde 2000 pesquiso o que denomino de profissionais transnacionais (Clemente, 2005, 2009), concentrando-me nos empregados de empresas transnacionais com atividades na cidade de São Paulo. O foco eram os trabalhadores estrangeiros contratados para cargos cuja norma era flexibilidade para se deslocar constantemente para diversos países do mundo, podendo ficar no novo país por poucos dias ou durante anos. Esses revelariam à antropologia uma vida de intensa mobilidade, que, no seu dia a dia, cria e recria formas de sociabilidade no e pelo desenvolvimento de suas atividades laborais, que os condiciona ao movimento transnacional.

Muitos trabalhadores embarcados são profissionais transnacionais e passaram a fazer parte do meu campo de análise a partir do momento da descoberta de reservas de présal pela Petrobrás entre 2005 e 2006, pois toda a movimentação da imprensa e do setor financeiro levou-me a perceber que nesse processo muitos estrangeiros movimentariam de novo o mercado de trabalho brasileiro.

Em 2010, com apoio do CNPq, resolvi iniciar uma pesquisa sobre as redes sociais formadas por profissionais transnacionais atuantes no desenvolvimento do pré-sal brasileiro, a qual gerou as análises que apresento neste artigo. 


\section{As primeiras inserções no universo petrolífero: iniciação na linguagem técnica e identificação dos espaços sociais}

A partir da aprovação da pesquisa pelo $\mathrm{CNPq}$, começou meu processo de imersão no universo petrolífero. Como já informado, eu vinha do estudo de profissionais transnacionais e é importante que o leitor saiba que, apesar de eles se deslocarem constantemente, moravam por certo período em locais fixos e trabalhavam em escritórios que ficavam em terra firme, situados, principalmente, na cidade de São Paulo. Mas como os chamados embarcados não apresentavam a mesma realidade, eu teria que adequar as estratégias de pesquisa.

As primeiras inserções em campo foram difíceis, pois precisei compreender a geografia dos trabalhadores petroleiros, seus espaços laborais e sociais.

Havia definido que iniciaria a etnografia na cidade de Santos, no Estado de São Paulo, supondo que, como a reserva de pré-sal localizava-se na Bacia de Santos, aí encontraria formas de sociabilidade desses profissionais. Assim, passei a frequentar a cidade com vistas a identificar os espaços sociais dos transnacionais.

Após algumas tentativas sem sucesso de estabelecer campo, sem ao menos conseguir identificar pontos de frequentação dos profissionais transnacionais, tal como havia feito na pesquisa anterior na cidade de São Paulo, achei importante procurar o escritório da Petrobrás em Santos em busca de informações sobre a atuação de trabalhadores estrangeiros na exploração das reservas do pré-sal, já que esses trabalhavam em uma das descobertas da empresa. Os contatos foram realizados, apesar de extremamente difíceis, pois os funcionários com os quais conversei demonstravam-se muito cautelosos no que diziam, denotando certo sigilo empresarial. Mesmo assim consegui obter algumas informações esclarecedoras e que permitiram pelo menos definir os primeiros passos a serem dados na execução da etnografia.

Nessas primeiras conversas com a empresa compreendi que a Bacia de Santos, onde se encontra a reserva de pré-sal, é uma área 
$\mid 46$ |

Faces do pré-sal brasileiro...

que se estende do estado de Santa Catarina ao estado do Espírito Santo e está a quase $400 \mathrm{~km}$ da costa brasileira.

O termo pré-sal refere-se a um conjunto de rochas localizadas nas porções marinhas de grande parte do litoral brasileiro, com potencial para a geração e acúmulo de petróleo. Convencionou-se chamar de pré-sal porque forma um intervalo de rochas que se estende por baixo de uma extensa camada de sal, que em certas áreas da costa atinge espessuras de até $2.000 \mathrm{~m}$. O termo pré é utilizado porque, ao longo do tempo, essas rochas foram sendo depositadas antes da camada de sal. A profundidade total dessas rochas, que é a distância entre a superfície do mar e os reservatórios de petróleo abaixo da camada de sal, pode chegar a mais de 7 mil metros ${ }^{2}$.

A reserva brasileira é a mais profunda do mundo, representando o maior campo petrolífero em águas ultraprofundas. Outras camadas semelhantes ao pré-sal já foram identificadas em outros locais do mundo (Litoral Atlântico da África, Golfo do México, Mar do Norte e Mar Cáspio) e em algumas dessas regiões foram encontrados indícios de petróleo, mas nada comparado às grandes reservas petrolíferas do litoral brasileiro.

A exploração da reserva brasileira ocorreria em regime de concessão, tendo a empresa petrolífera Petróleo Brasileiro S/APetrobrás como sua operadora única, que, em sistema de partilha, unir-se-ia a outras empresas através de consórcios cujos contratos garantissem no mínimo 30\% de operações da Petrobrás em cada exploração de campo do pré-sal, estando a Bacia de Santos dividida, até o momento, em nove campos: Tupi, o primeiro a ser descoberto e que atualmente se chama Lula, Azulão, Bem-te-vi, Caramba, Carioca, Guará, Iara, Júpiter e Parati, como demonstra a figura 1.

\footnotetext{
${ }^{2}$ Ver informações do Pré-sal no site www.petrobras.com.br.
} 


\section{Figura 1}

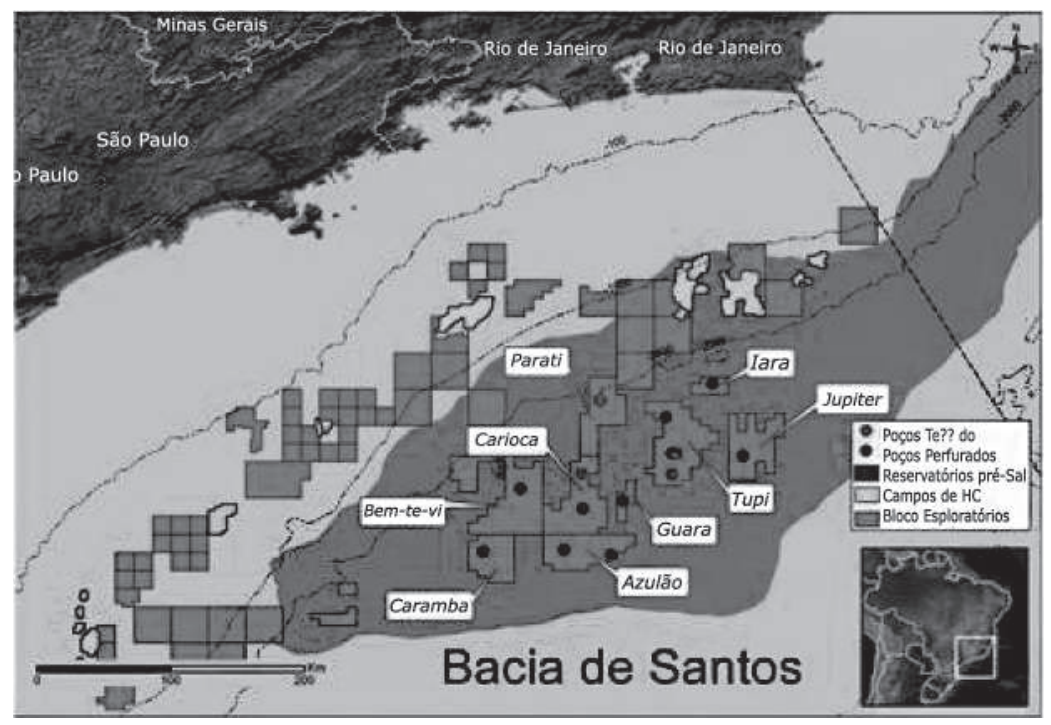

Fonte: Revista TNPetroleo

Cada campo contém uma empresa consorciada que desenvolve as atividades, a princípio, de pesquisa e exploração do mineral.

Os trabalhadores estrangeiros que comporiam a pesquisa são parte desse universo e, na sua grande maioria, são funcionários de empresas estrangeiras consorciadas ou das que fazem parte da cadeia produtiva.

Mesmo com posse dessas informações eu ainda precisava ver e observar a sociabilidade desses trabalhadores. Na cidade de Santos é imperceptível a mão de obra estrangeira atuante no pré-sal. Pouco a pouco constatei que os profissionais estrangeiros transnacionais envolvidos na exploração do pré-sal e baseados naquela cidade eram, e ainda são atualmente, poucos e, se eu quisesse realmente me aproximar de uma experiência 
social terrestre desses trabalhadores offshore, não seria nas cidades da Baixada Santista.

Essa invisibilidade do objeto é algo recorrente nas pesquisas sobre a mão de obra transnacional, o que já havia sido constatado por autores como Tarrius (1992) e Kennedy (2004).

Enquanto dado quantitativo, também são praticamente invisíveis nas estatísticas laborais oficiais e recebem atenção de consultorias especializadas em "expatriados", termo utilizado pelo mercado para definir esse tipo de trabalhadores. De acordo com uma dessas consultorias, a Mercer, citada pelo jornalista Vanderlei Abreu da revista Melhor na versão online de agosto de 2009, o número de deles no período de 2008/2009 chegou a 94 mil indivíduos (Abreu, 2008).

Apesar de diminutos em relação a outros números do universo do trabalho e das migrações, os transnacionais atuam em áreas de grande atração financeira e a invisibilidade da qual desfrutam é importante para o desenvolvimento de seu trabalho e manutenção de certos segredos empresariais.

Outro ponto que merece atenção é que a entrada seletiva desses profissionais em diversos países indica que a mobilidade de uma mão de obra de alta qualificação é encorajada como um aspecto importante para o fortalecimento de um mercado e de um tipo de cultura transnacional.

Nesse mapa transnacional, o Brasil figura com um dos países disponíveis à globalização econômica. Efetivamente, observou-se que a onda de privatizações das estatais brasileiras e a abertura do setor de telecomunicações (telecoms), iniciada na metade dos anos 1990, atraiu para o país um significativo segmento da mão de obra estrangeira.

Reportagens daquele periodo já retratavam a entrada dessa mão de obra qualificada, como a da jornalista Nely Caixeta na revista Exame de 9 de agosto 2000, versão on-line:

O Brasil tornou-se o destino de uma nova maré de imigrantes do mundo inteiro. (...) Há neste momento, segundo estimativas do Ministério do Trabalho e 


\begin{abstract}
Emprego, um total de 19.000 profissionais estrangeiros com visto temporário para exercer seu ofício no país. Em comparação com os imigrantes que aportaram por aqui, em diferentes levas, no período compreendido entre o final do século passado e o pós-guerra, tratase de um contingente acanhado. Todos unidos ocupariam apenas a metade do Estádio do Pacaembu, em São Paulo. O que distingue esses estrangeiros de agora é que, em vez da enxada do trabalhador da lavoura do passado, a maioria chega com seus laptops e Palm Pilots, títulos de especialização pelas melhores universidades, experiência profissional apurada em passagens por vários continentes e uma noção clara do que significa operar num cenário de competição global. (Caixeta, 2000, s/p., versão on-line)
\end{abstract}

Esse processo de encorajamento do deslocamento de trabalhadores qualificados não está dissociado dos interesses mercantis e culturais de empresas transnacionais, como analisa Yves Dezalay (2004):

Les stratégies internationales sont des stratégies de distinction pour un petit groupe de privilégies, auquel s'impose un minimum de discrétion sur ce qui fonde leurs privilèges, afin de pouvoir continuer à pratiquer le double jeu du national et de l'international: investir dans l'international pour renforcer leurs positions dans le champ du pouvoir national et, simultanément, faire valoir leur notoriété nationale pour se faire entendre sur la scène internationale. Pour réussir ce coup double, il doivent cultiver à la fois la proximité et la distance avec leurs concitoyens pour convaincre que non seulement ils partagent les mêmes valeurs, mais aussi qu'ils sont les mieux à même de promouvoir les intérêts nationaux dans la compétition internacionale. ( Dezalay, 2004, p. 11)

Em busca desse prestígio, referendado pelas elites nacionais, os profissionais transnacionais com cargos executivos dominam 
maneiras eficazes de adentrar fronteiras culturais e linguísticas, usando seus conhecimentos e estratégias cosmopolitas na maioria das vezes cultivados na juventude, enquanto alunos das escolas de negócios. Conseguem, assim, acesso a estágios em empresas no exterior, formação cujo custo é altíssimo.

As estratégias de internacionalização dos interesses capitalistas promovem "a unificação do campo mundial da formação dos dirigentes" (Bourdieu apud Dezalay, 2004, p. 8).

Cabe ressaltar que a reprodução dessa mão de obra qualificada não é calcada somente na riqueza material, nos bons negócios. O capital econômico deve ser legitimado e mesclado por competências que permitam ao profissional ter habilidades para lidar com contextos culturais diferenciados, com formas de negociar que são diferentes de país para país.

A literatura para profissionais transnacionais de nível executivo recomenda que, para entender a outra cultura, o transnacional precisa ingressar nela. Para isto, é preciso manter contato com o local, contatos por vezes artificiais, como almoçar em restaurantes cuja clientela é formada por pessoas das elites locais, mas com o objetivo de formar uma competência intercultural que seja útil na relação com um outro que, na maioria das vezes, é aquele que faz parte de um grupo seleto da sociedade local.

Assim, a elite dos profissionais transnacionais, nas suas relações cotidianas de trabalho, deve pensar em interagir com os segmentos sociais nicho, porque seu trabalho e os produtos que a empresa para a qual trabalha produz não são para todos.

Para domínio dessas competências, os profissionais transnacionais investem grandes fortunas em cursos que os capacitem e os dotem de habilidades que permitam seu reconhecimento no mercado internacional. "O mercado dos especialistas internacionais é um mercado elitista, protegido por barreiras discretas mas eficazes. Para acessá-lo, é necessário dispor de competências culturais". (Dezalay, 2004, p. 29)

Tanto para aqueles profissionais internacionais que nasceram em grandes famílias empresariais quanto para os de origem média, 
o investimento em uma educação para a globalização constitui algo importante.

A empresa transnacional é outro espaço de produção e reprodução desse poder. Nela trabalha e é produzida (ou seja, lapidada) a mão de obra internacional. Entendemos que à empresa transnacional cabe, a partir de sua cultura institucional, modelar o profissional, garantindo que ele mantenha uma criatividade eficaz no atendimento dos interesses empresariais que devem ser concretizados nos diferentes mercados nacionais.

Mesmo nas empresas que põem em movimento transnacional diversos níveis de profissionais - operários, técnicos, gerentes e diretores -, a discrição quanto aos assuntos do trabalho é algo comum a todos os níveis hierárquicos. Não se pode transmitir informações sigilosas a todos do seu meio social. Não é interessante ser reconhecido e indagado das atividades que realiza. Então, manter-se na invisibilidade é algo necessário aos negócios da empresa.

Tal questão é significativa porque, embora muitas análises apontem que esse tipo de comportamento sigiloso é algo partilhado pelos profissionais com posições mais elevadas na empresa, não é bem essa a realidade, tanto que isso foi o que mais me chamou a atenção no setor petrolífero.

Para driblar a invisibilidade dos profissionais transnacionais offshore associada ao seu baixo número na Baixada Santista e a cautela empresarial no fornecimento de dados que possibilitassem meu acesso aos trabalhadores, resolvi deslocar minhas atividades etnográficas para uma região significativa para exploração e produção de petróleo no Brasil, a Bacia de Campos.

De acordo com a Petrobrás, a bacia de Campos é uma área sedimentar que se estende de Vitória/ES a Arraial do Cabo/RJ, numa área de aproximadamente $100 \mathrm{mil} \mathrm{km}^{2}$, onde se desenvolve boa parte da produção de petróleo e gás do Brasil, o que a torna a principal bacia produtora nacional.

O primeiro campo com potencial comercial da bacia de Campos foi Garoupa, descoberto em 1974, e de lá para cá ouros 
campos foram descobertos e todos batizados com nomes de peixes. O site da Petrobrás ressalta:

Nesse gigantesco laboratório a céu aberto testamos as principais tecnologias offshore experimentadas no desenvolvimento de projetos de produção à profundidade d'água nunca testados anteriormente no mundo. ${ }^{3}$ (Bacia de Campos, Site Petrobrás, 2011).

É nesse laboratório que estavam fincadas as bases tecnológicas da camada pós-sal e, além disso, também as parcerias transnacionais para o desenvolvimento do pré-sal. Devido a esse contexto, considerei que a região da Bacia de Campos, em específico a cidade de Macaé, apresentava uma vida social marcada por experiências ligadas ao trabalho com o petróleo, oferecendo um ambiente propício a uma etnografia inicial.

Lá eu não só encontraria a sociabilidade cultivada por esse tipo de trabalhador, como entenderia melhor sua rotina de trabalho.

Macaé também tinha mais um atrativo: todas as empresas estrangeiras ligadas ao pré-sal que atuam no Brasil têm escritório na cidade. Algumas também possuem outro escritório na cidade do Rio de Janeiro.

Enfim, parti para cidade de Macaé para iniciar minhas observações etnográficas.

\section{Apreciando o movimento, produzindo etnografia}

Pelo céu de Macaé, movimentado pelo trânsito intenso de helicópteros, já se tem uma noção de estar em uma cidade movida pela exploração offshore do petróleo. É um leva e traz de passageiros às plataformas e navios-sonda instalados no mar. Todo

\footnotetext{
${ }^{3}$ Ver informações da Bacia de Campos no site da Petrobras www.petrobras. com.br.
} 
dia é isso, de domingo a domingo, no céu o movimento frenético dessas aeronaves. Lá de vez em quando passa um avião, mas o céu não fica nem uma hora livre.

Pela visão do céu tracei minhas primeiras incursões etnográficas, que foram feitas nas dependências do aeroporto/ heliporto de Macaé, de onde partem as aeronaves que transportam os trabalhadores offshore. Lá me deparei com um ambiente que me revelou parte significativa das experiências sociais desse contingente laboral.

Na sala de embarque há sempre muitos homens de idades variadas, desde jovens na faixa dos 21 anos a homens em idade de se aposentar. Poucas mulheres, contam-se nos dedos as representantes do gênero feminino naquelas centenas de figuras masculinas que se reúnem nos vários horários das tabelas de voos.

Eu sempre chegava com ar de que ia buscar alguém no desembarque e depois me deslocava pelo aeroporto, dividindo períodos de tempo entre a sala de embarque e a de desembarque.

O heliporto de Macaé serve tanto ao transporte de trabalhadores da Petrobrás, como das empresas estrangeiras que atuam nas bacias de Campos e Santos. Há outros heliportos que atendem esse público, mas, com já afirmei, escolhi observar o macaense.

A centena de homens que lá passam, nos vários horários do dia, variam na idade e também na nacionalidade. Há muitos estrangeiros e, por meio de minhas abordagens realizadas na primeira visita e nas outras que se seguiram, consegui constatar que os que mais se destacavam eram ingleses, americanos, noruegueses, indianos e demais asiáticos, como filipinos, chineses etc.

A presença escandinava é recorrente e antiga nesse cenário offshore brasileiro, segundo informações de funcionários aposentados da Petrobrás, especialmente os noruegueses, que sempre estiveram presentes nas contribuições técnicas na exploração do mineral na Bacia de Campos. Americanos e ingleses também, e agora, com o pré-sal, mais intensas ficaram as relações com essas nacionalidades. Uma funcionária da Petrobrás 
informou-me certa vez que sempre foi comum observar nas plataformas equipes de trabalho formadas por um chefe europeu (norueguês), técnicos qualificados de nacionalidades variadas e operadores asiáticos (indianos, filipinos etc.). Relações que eu constatava naquele heliporto macaense.

Os momentos de embarque também guardam uma riqueza etnográfica, pois se sente uma certa tensão entre os trabalhadores. Telefonemas são dados e atendidos tratando de assuntos de conteúdo afetivo e de questões materiais. Uma vez escutei alguém dizer que estava virado, ou seja, havia dobrado noites de trabalho e não iria dar tempo de descansar e de dormir em casa porque tinha que voltar para a plataforma e fazer hora-extra para pagar um carro usado que havia comprado.

Há muita gente cabisbaixa também, olhares distantes, rostos de fadiga. Uma das vezes conversei como uma geóloga argentina que faria o acompanhamento de uma sonda na perfuração de um poço. Não sabia quanto tempo ficaria no navio-sonda, a princípio 15 dias, mas as notícias eram de que poderia ficar mais. Segundo ela, já estava com saudades dos filhos e da família, que permaneciam na Argentina. Ela tinha passado rapidamente por Macaé, uma noite, só para dormir, e naquele dia embarcaria para o navio-sonda.

No período que estive em Macaé, não consegui autorização para deslocar-me para a plataforma, por isso cabe citar as informações quanto a esse tipo de translado descritas pela assistente social da Petrobrás, Rose Mery dos Santos Costa Leite, em seu livro Bandeirantes do Mar:

O deslocamento entre aeroporto e a plataforma se dá em voos de helicóptero, com duração entre 40 a 90 minutos (...) quando se chega no aeroporto já existe toda uma padronização de procedimentos a serem seguidos. $O$ trabalhador localiza num quadro de avisos o seu voo e dirige-se ao local de pesagem dos passageiros e bagagens. A bagagem está limitada a $15 \mathrm{~kg}$, é pesada e vistoriada, uma vez que é terminantemente proibido o transporte, por exemplo, 


\begin{abstract}
de armas, bebidas e drogas. Posteriormente, após a chamada de seu voo, o trabalhador encaminha-se para a área interna de espera, onde é submetido à revista por um segurança. Algum tempo depois, já na aeronave, recebe o colete inflável, a ser colocado imediatamente e assiste ao 'briefing' de segurança do copiloto. (Leite, 2009, p. 97/98).
\end{abstract}

E assim partem para seus dias de trabalho offshore.

O deslocamento para o mar impõe a esses trabalhadores outros deslocamentos nas dimensões subjetiva, temporal e relacional e requer deles arranjos existenciais e sociais que permitam viver no mar na companhia de outros na mesma condição sob as prescrições temporais empresariais.

Segundo Leite, durante o período de trabalho offshore,

\begin{abstract}
permanecerão sem contatos pessoais com amigos de terra, familiares etc, sem ingerirem nenhuma bebida alcoólica, folgarem os finais de semana e feriados, comemorarem datas importantes, assistirem de perto os seus times jogarem e, muito menos, faltarem ao trabalho, pois estarão isolados envoltos pelo metal, pelo azul do céu e o azul-marinho do mar. (Leite, 2009, p. 99/100).
\end{abstract}

Sem esquecer que o mar constitui um espaço que impõe ao ser terrestre um conjunto de desafios: aquosidade, profundidade, enfim, elementos não familiares que, no caso do trabalhador petroleiro, agravam um quadro de riscos impostos pelo próprio desenvolvimento das atividades petrolíferas, expostas a acidentes que infelizmente podem acontecer a qualquer momento.

Esse ambiente marítimo e suas condições de trabalho pode acentuar o que Lociser (1997) denomina efeito totalizante que recai sobre os trabalhadores offshore. Elemento que, de acordo com Carvalho (2010, p. 42), é fruto de uma não dissociação do exercício profissional e as atividades fora do trabalho.

Quando desembarcam, muitos não têm casa e/ou família em Macaé. Nesse caso, alguns ficam em "repúblicas de embarcados" 
ou nas pousadas e hotéis da cidade, que se localizam em grande parte nas proximidades da praia de Cavaleiros ou na sua própria orla. Outros partem diretamente para suas cidades de origem, muitas delas fora do Brasil. Esse foi o caso de um jovem americano, amigo de uma das minhas informantes moradora de Macaé. $\mathrm{O}$ americano desembarcava e passava algumas horas na cidade, nas quais às vezes até se divertia nos bares e danceteria locais e depois seguia para os EUA, aproveitando para dormir no voo até seu país de origem. Como ele, observei vários outros estrangeiros nessa situação, desembarcados e frequentadores de um café famoso entre os estrangeiros e próximo da orla da praia de Cavaleiros.

São vários os estabelecimentos voltados ao lazer de quem vai passar apenas algumas horas na cidade e mesmo daqueles que resolvem gastar o que ganharam em dias trabalhados. Muitas são as histórias que comerciantes contam de pessoas que gastaram o salário numa noite de alegrias.

Já os que moram nas cidades da região da bacia de Campos passam parte do tempo de folga de 15 ou 21 dias de certa forma driblando as diferenças temporais de seus familiares e amigos, pois a maioria desses trabalha 40 horas semanais e folga em finais de semana ou está trabalhando quando os offshore estão de folga.

As idas e vindas do mar são momentos que demarcam, para o trabalhador offshore, tempo de despedida e tempo de recomeço. Despedida dos dias de folga, da terra, da família e dos amigos do continente para retorno ao mar, recomeçando o trabalho e os vínculos com colegas de unidade marítima.

Isso requer que tenham uma atitude de artesão com seus afetos, que os reconstruam nas idas e vindas, nas despedidas e recomeços.

Constatei na observação etnográfica que a superação desses momentos vem através dos vínculos de amizade. Neles é que encontram conforto para superar as condições de um trabalho transnacional offshore.

Os vínculos fraternais, as amizades no mar ou na terra oferecem âncoras de sustentação para as suspensões afetivas às 
quais estão sujeitos esses trabalhadores, pois ora vivem as tensões pré-embarque, ao se despedir de seus afetos, ora vivem a tensão do desembarque, marcada por euforia, bebedeiras, excessos ou apatia, que expressam um estado fora da estrutura cotidiana.

Em todos os espaços, há amizade, seja aquela dos amigos de plataforma que celebram ou que juntos descarregam seus fardos de trabalho no desembarque, seja a dos amigos da terra, que os apoiam em seus momentos de alegria ou de frustração afetiva, quando o cônjuge se deprime com os afastamentos constantes do companheiro ou companheira.

A amizade não é incompatível do modo de vida dos trabalhadores transnacionais.

Observa-se que, mesmo que esses façam intensas viagens, efetuem contínuas mudanças de moradia e de país, seus vínculos de amizade estão entre os mais duradouros. Na verdade, é porque esse sentimento pressupõe abertura e liberdade. A amizade ama o encontro, mas suporta a partida.

Francesco Alberoni ao analisar a amizade afirma:

Temos plena consciência queoencontro foi significativo. Mas não desejamos prolongá-lo ilimitadamente. Sabemos que sua natureza é descontínua. Não quer dizer que não desejamos tornar a encontrar o amigo. A simpatia de um encontro projeta-se no futuro, quer reencontrar, é uma experiência global, de completeza. Mesmo que aconteça num instante e só dure um instante, abraça a diversidade caótica da nossa vida e lhe impõe ordem, confere-lhe significado. (Alberoni, 1993 p. 17-8)

Sabe-se que muitos dos momentos da vida de um trabalhador transnacional são marcados por descontinuidades: ora está em mares brasileiros, ora em mares tailandeses. Nesses deslocamentos, muitos dos vínculos locais desmaterializamse, mas algo permanece, e este algo é a amizade que, entre essas pessoas, ganha dimensão transnacional. 
$|58|$

Faces do pré-sal brasileiro...

\begin{abstract}
A afinidade profunda que sentimos com o outro durante o encontro não resulta do fato de que ele está buscando exatamente as mesmas coisas que nós, que tem os nossos mesmos objetivos e nossos mesmos desejos. O encontro é reconhecer uma identidade ou uma semelhança. É perceber que o outro nos complementa e nós nos complementamos (...). O encontro é percorrer um trecho de estradas juntos no sentido da própria identidade, no sentido da descoberta daquilo que, para cada um, é a coisa mais importante. No encontro nós descobrimos que estamos lado a lado contra uma obscuridade ou um inimigo. (Alberoni, 1993, p. 14).
\end{abstract}

Contatos e vínculos são reativados nas idas e vindas, para que se realizem esses movimentos.

Há nisso tudo o confortável espaço da amizade, lugar de escuta e de aconselhamento fraternal. Muitas vezes, proporcionam um suporte afetivo.

As expressões dessas experiências afetivas são possíveis de serem observadas no cotidiano de Macaé, na orla da praia de Cavaleiros. Nesse local encontram-se vários equipamentos de lazer e a possibilidade de olhar o mar a partir do continente, criando uma atmosfera propicia aos encontros e caminhadas reflexivas.

\title{
Trabalho Offshore e sociabilidade urbana
}

A orla da praia de Cavaleiros é onde se pode observar outras facetas que envolvem o trabalhador offshore.

$\mathrm{O}$ ambiente da orla continua com a forte presença masculina, tal qual o heliporto, mas há mais mulheres que no heliporto, até porque o lugar constitui-se como uma área de diversão dos habitantes locais e de pouquíssimos turistas. Então é normal ver um número maior de mulheres, mas esse contingente não supera o de homens. 
Nos aproximadamente $6 \mathrm{~km}$ de orla envolvendo as praias de Cavaleiros e do Pecado, chamam a atenção as várias formas de sociabilidade e as fronteiras que delimitam os territórios sociais de grupos diversos que se diferenciam por poder aquisitivo, idioma e estilos de vida. Essa diversidade cultural e as nuances econômicas do mundo offshore são observadas ao ver as escolhas dos transeuntes por bares, restaurantes e hotéis a serem utilizados para seu lazer e descanso.

Em termos de infraestrutura, esse espaço praiano macaense contém uma rede de hotelaria refinada, oferecendo tanto leitos em ambientes de 3 a 5 estrelas, quanto uma rede de pousadas simples, confortáveis, mas com preços médios. Possui também muitos bares e restaurantes caros e alguns botecos de preço mediano que reúnem mais pessoas.

Ao transitar pela orla, pude observar que aqueles que ocupavam cargos mais elevados no trabalho offshore frequentavam determinados restaurantes cujos cardápios, apresentados na entrada do local, descreviam pratos de preços altíssimos, inibindo o público de médio poder aquisitivo.

A população pobre da cidade, que se encontra na grande maioria distribuída nos bolsões de pobreza de Macaé, não frequenta esses lugares. Mesmo eu, pesquisadora, tive impedimentos financeiros para frequentar alguns locais daquela orla e, para o desenvolvimento do trabalho etnográfico na região, tive que usar estratégias como caminhar e fazer várias pausas em que me sentava nos bancos e apreciava o movimento das pessoas, sua entrada e saída dos hotéis e restaurantes caros.

Foi ao apreciar o movimento das pessoas que identifiquei a existência de nichos de lazer, diversão e hotelaria que atendiam públicos específicos. Constatei que, após saírem do restaurante caro, alguns se dirigiam a hotéis de 4 a 5 estrelas. Durante o trajeto do restaurante ao hotel ou vice-versa, esses grupos conversavam em inglês, mas também era possível ouvir idiomas escandinavos.

Acompanhei alguns desses trajetos durante os momentos de minhas caminhadas. Praticamente seguia alguns poucos grupos de amigos e o fiz da seguinte forma: ora fazia minha pausa da 
$|60|$

Faces do pré-sal brasileiro...

caminhada diante de algum dos hotéis e aguardava um indivíduo ou grupo sair, reiniciando então a caminhada, ora ficava nos bancos de frente aos restaurantes e/ou bares e, quando alguém saia, eu reiniciava a caminhada até o local em que ele(a) se hospedava.

Pode soar meio estranha essa estratégia, mas serviu para driblar meus impedimentos financeiros. Fiz algo parecido com as danceterias, frequentando o lado de fora delas, como se estivesse esperando alguém ou fazendo um tipo "esquenta" antes de entrar. E assim escutava algumas conversas e exercitava o diálogo quando era possível.

Nessas inserções etnográficas, às vezes eu contava com a companhia de minhas informantes, mas na maioria das vezes estava sozinha.

Essas práticas sociais exercidas no tempo livre desses trabalhadores ganham mais público em épocas de feiras e fóruns offshore que se instalam na cidade de Macaé. É famosa, por exemplo, a feira bienal Brasil Offshore, que reúne gente de todo o mundo. Tive oportunidade de frequentar e participar da feira que aconteceu em junho de 2011.

Os trabalhadores e as populações de cidades construídas em torno do desenvolvimento do petróleo, como é o caso de Macaé, dedicam parte de seu calendário social a esses eventos ligados à produção e à exploração de petróleo e de gás natural.

As feiras, encontros e conferências dedicadas ao universo offshore mobilizam quase toda a população dessas cidades petrolíferas, levando famílias, seus jovens, na maioria estudantes do ensino médio e universitário, e também seus adultos a esses eventos cuja duração, na maioria das vezes, é de uma semana.

Para mim, acompanhar a Brasil Offshore foi uma excelente oportunidade para observar a organização da feira, a atuação das empresas estrangeiras e os produtos que são ofertados ao seu variado público.

Destaco que me chamou atenção o valor cobrado pelo ingresso de uma palestra: aproximadamente mil reais. Geralmente elas são dadas por pesquisadores e profissionais contratados das 
empresas estrangeiras e muito poucos pesquisadores e professores com vínculos universitários.

Evidentemente, não tive condições de participar de nenhuma palestra e também não era meu objetivo fazê-lo. O que fiz foi acompanhar a movimentação das pessoas, suas conversas nos espaços de pausa e coffe break, pois havia áreas livres e de circulação gratuita para pós-graduandos e professores.

As feiras offshore também permitiram iniciar minhas primeiras inserções etnográficas na Baixada Santista no estado de São Paulo, pois foi através da Santos Offshore, ocorrida em outubro de 2011, que me reinseri no campo etnográfico da região.

Por meio dessa feira de Santos, que é um evento de negócios por excelência, percebi haver uma configuração política e social diferente daquela observada em Macaé.

De imediato me chamou a atenção o fato de as palestras serem gratuitas e haver uma forte presença, entre os palestrantes, de representantes do governo do estado paulista, professores universitários e profissionais de escolas técnicas.

Havia também alguns poucos funcionários da Petrobrás. A estrutura do evento era mais simples e com menos expositores que a de Macaé. Santos ou a Baixada Santista revelariam uma outra apropriação dos frutos do petróleo, diferentemente de Macaé e das demais cidades cariocas, que estão envolvidas na produção petrolífera da bacia de Campos.

As cidades paulistas são, e muitas certamente o serão, palco da vida social dos trabalhadores do pré-sal da bacia de Santos, mas apresentam ainda, nesse início de atividades no setor, uma certa distância do universo petrolífero.

Não se respira petróleo no dia a dia da vida social da Baixada Santista, tal como nas cidades que envolvem a Bacia de Campos.

O que se observa nessa região paulista é uma mobilização dos setores imobiliário e educacional. Quanto a esse último, as universidades e escolas locais estão cada vez mais empenhadas na elaboração de cursos que venham a formar mão de obra para o petróleo e também em fornecer serviços educacionais para as famílias transnacionais. 
Do meu ponto de vista, os negócios do petróleo nas cidades da Baixada Santista estão ainda no nível do segredo.

O segredo é algo comum nos ambientes de grandes negócios, o que acaba gerando níveis de invisibilidade do que está sendo negociado e das atividades que fomentam o desenvolvimento do negócio.

Não que não existam segredos nas várias frentes que fomentam a produção e exploração offshore em Macaé/RJ, mas a vida social daqueles que vivem do trabalho nesse setor atinge aí maior visibilidade que em Santos/SP.

Por fim, voltar-se para a experiência desses trabalhadores de empresas transnacionais offshore, que se tornam capazes de estar aqui e de estar lá, de entrar e sair de ambiente de trabalho com experiências totalizantes e adentrar a sociabilidade que flui fora do trabalho permite compreender diferentes configurações sociais e simbólicas que emergem na atualidade.

\section{Bibliografia}

ABREU, V. Pesquisa sobre expatriação Disponível em: http://www.revistamelhor.com.br/textos/253/artigo223461-1. asp. Acesso em 12/07/2012.

ALBERONI, F. A amizade. Rio de Janeiro: Rocco, 1993.

BACIA DE CAMPOS. Disponível em <http://www.petrobras. com.br/pt/quem-somos/principais-operacoes/?category $=0>$. Acesso em 03/03/2012.

BIDART, Claire. L'amitié, un lien social. Paris, Editions La Decouverte, 1997.

CAIXETA, Nely. Os novos imigrantes. Exame, ed. 720, 9/8/2000. Disponível em: <http://www.exame.com.br> acesso em 11/12/2011. 
CARVALHO, M. M. Vida e trabalho marítimos embarcados do setor offshore (Mestrado) apresentado Escola Nacional de Saúde Pública Sérgio Arouca, Rio de Janeiro, 2010.

CLEMENTE, Claudelir C. A vida social transnacional. Tese de doutorado. Pontifícia Universidade Católica de São Paulo, São Paulo, 2005.

Sociabilidades que cruzam fronteiras: profissionais transnacionais. In: Diásporas, redes e guetos: conceitos e configurações no contex to transnacional. Bernardo T. e Clemente, C. (orgs). São Paulo, EDUC/CAPES, 2008.

. Natifs de la transnationalisation. Revue Hommes e Migrations, Paris, France, n. 1281, 2009.

CLEMENTE, C. C. e GARCIA, T. Perspectivas antropológicas sobre o pré-sal brasileiro: primeiras inserções no universo petrolífero. Revista Horizonte Científico, vol. 6, ano 2012.

DEZALAY, Yves. Les courtiers de l'internacional: heritiers cosmopolites, mercenaires de l'imperalisme et missionaires de l'universel. Sociologie de la mondialisation. Actes de la Recherche. n. 151-2, mar. 2004.

FAVELL, A. The human face of global mobility. In: Smith, M. P, and Favell, A. (eds), In. The Human Face of Global Mobility. Transaction Publishers: New Brunswick, NJ. 2006.

FREITAS, CM., Souza CAV, Machado JMH, Porto MFS. Acidentes de trabalho em plataformas de petróleo da Bacia de Campos. Cad. Saúde Pública. 17:117- 130. 2001.

KENNEDY, P. Making global society, In. Global Networks, v. 4, 2, Spring 2004.

LEITE, R. Mery S. C. Bandeirantes do mar: identidade dos trabalhadores das plataformas. Niterói: Intertexto, 2009. 
|64 |

Faces do pré-sal brasileiro...

LOSICER, E. A procura da subjetividade: a organização pede análise. In: Davel, E. \& Vasconcellos, J. (Orgs.). Recursos humanos e subjetividade. Petrópolis: Vozes, 1997.

PETROBRÁS. www.petrobras.com.br

PRÉ-SAL Disponível em: <http://www.petrobras.com.br/minisite/presal/ pt/perguntas-respostas/>. Acesso em 03/03/2012.

TARRIUS, A. Les fourmis d'Europe. Paris: L'Harmattan, 1992. 